Racic 5 (2) (2020)
JURNAL RAB CONTRUCTION RESEARCH
Uttp://jurnal.univrab.ac.id/index.php/racic
ABDURRAB

\title{
TINJAUAN PENETRASI INDEKS ASPAL TERHADAP PENAMBAHAN LIMBAH POME
}

\author{
Alfian Saleh $^{1}$, Muthia Anggraini ${ }^{2}$ \\ Program Studi Teknik Sipil, Fakultas Teknik, Universitas Lancang Kuning \\ Jl.Yos Sudarso Km.8 Rumbai-Pekanbaru \\ Telp (0761) 53108-53236 \\ Alamat e-mail ${ }^{1}$ alfian.saleh@unilak.ac.id, ${ }^{2}$ muthia@unilak.ac.id
}

\begin{tabular}{l}
\hline Info Artikel \\
\hline \\
Sejarah Artikel: \\
Diterima :Juli 2020 \\
Disetujui : Desember 2020 \\
Dipublikasikan : Desember \\
2020
\end{tabular}

Keywords:aspal, limbah pome, Index penetration
Sekitar 4-10\% kadar aspal merupakan penentu kinerja pada lapis perkerasan lentur. Ketersediaan aspal semakin lama semakin berkurang untuk itu perlu adanya upaya dalam pemanfaatan aspal. Salah satu cara yang dilakukan adalah dengan penambahan limbah. Sifat aspal yang sangat penting dilihat pada nilai penetrasi dan titik lembek aspal. Nilai penetrasi dan titik lembek pada aspal murni Pen.60/70 sebesar $62,2 \mathrm{~mm}$ dan $48,5^{\circ} \mathrm{C}$ kemudian sebanyak $1 \%, 2 \%, 3 \%$, 4\% dan $5 \%$ ditambahkan limbah pome. Dari penambahan limbah pome ini untuk nilai penetrasi mengalami penurunan sedangkan untuk titik lembek dengan penambahan limbah pome ini mengalami kenaikan. Untuk nilai penetrasi indeks dengan penambahan limbah pome ini nilai penetrasi indeksnya mengalami kenaikan dari -0,686 untuk aspal tanpa penambahan limbah pome naik menjadi 0,245 pada penambahan $5 \%$ ini mengindikasikan bahwa dengan penambahan limbah pome tersebut membuat aspal memiliki sifat sensitif terhadap temperatur.Sehingga aspal yang digunakan harus memperhatikan temperatur saat proses pencampuran dan pemadatan.

Kata Kunci: Aspal, Limbah Pome, Index Penetration 


\begin{tabular}{lr}
\hline & Keywords: Asphalt, Pome waste, Penetration Indeks \\
\cline { 2 - 3 } & C) 2020 Universitas Abdurrab \\
\hline Alamat korespondensi: & ISSN 2527-7073 \\
Jl.Yos Sudarso Km.8 & \\
Rumbai-Pekanbaru & \\
e-mail 1alfian.saleh@unilak.ac.id &
\end{tabular}

\section{PENDAHULUAN}

Aspal merupakan material yang bersifat thermoplastis yaitu akan menjadi cair apabila dipanaskan dan mengeras pada suhu ruangan. Aspal berfungsi sebagai bahan pengikat dan pengisi pada rongga-rongga agregat. Kerusakan yang terjadi pada perkerasan diakibatkan oleh pemadatan dan temperatur yang berlebihan atau temperatur yang terlalu dingin dari yang dibutuhkan. Namun pada kenyataannya keberadaan aspal yang berasal dari fosil lambat laun akan semakin berkurang karena tidak dapat diperbaharui sehingga perlu adanya usaha dalam membuat aspal dapat diperbaharui dengan menambahkan bahan tambah dalam mendukung perkuatan perkerasan aspal. Bahan tambah yang digunakan sebaiknya merupakan bahan tambah yang dibuang dan menjadi limbah sehingga nantinya bahan tambah ini akan memilki nilai manfaat yang lebih, Fauziah, M., \& Emsya, Y. D. (2010).

Limbah merupakan suatu zat yang telah mengalami proses produksi dan kemudian dibuang karena dianggap tidak memiliki nilai ekonomi. Bentuk limbah padat dan cair dihasilkan dari produksi pengolahan pabrik kelapa sawit. Palm Oil Mill Effluent (POME) yang berbentuk cair ini merupakan limbah agroindustri pengolahan kelapa sawit menjadi minyak nabati. Dari dua ton minyak kelapa sawit dapat memproduksi lima ton limbah cair. Pome berasal dari proses pemisahan dan eksplanasi serta sterilisasi. Zat sisa ini umumnya memiliki suhu yang tinggi sekitar $70-80^{\circ} \mathrm{C}$, berwarna coklat pekat, menyimpan zat padat yang larut dan tersuspensi menghasilkan koloid dan residu minyak Susilawati, \& Supijatmo. (2015). Pada penelitian yang telah dilakukan pada aspal RAP dengan penambahan limbah Waste Cooking Oil (WCO) yang merupakan limbah dari minyak kelapa sawit bahwa WCO dapat dimanfaatkan sebagai bahan peremaja pada lapisan perkerasan dimana hasilnya sesuai dengan satndar Bina Marga, Fauziah, M., \& Emsya, Y. D. (2010).

\section{TINJAUAN PUSTAKA}

\section{Aspal}

Cairan hydrocarbon yang terlarut dalam trichloro-ethylene, tidak mudah menguap dan mencair jika dipanaskan yang merupakan sifat dari material aspal. Selain itu juga bersifat rheologic 
yang merupakan adanya hubungan antara tegangan dan regangan. Aspal memiliki sifat thixotropy apabila didiamkan.Tanpa adanya tegangan dan regangan akan berakibat aspal menjadi mengeras. Aspal adalah bagian yang kecil dari komposisi campuran lentur, tetapi bagian terpenting untuk mengikat material agar awet dan tahan lama (durable) serta memastikan campuran perkerasan lentur terjaga elastis. Aspal memiliki fungsi berbeda pada saat proses pencampuran. Pada proses prahampar aspal yang dipanaskan yang campur dengan agregat akan mengisi dan meresap pada pori antar butiran Rusbintardjo, G. (2013)

\section{Palm Oil Mill Effluent (POME)}

Limbah pome adalah produk yang dibuang dalam pengolahan kelapa sawit menjadi minyak nabati. Pome merupakan produk sisa berbentuk cair dari proses pengolahan minyak kelapa sawit yang menyebabkan polusi terbesar. Pome tersebut umumnya dihasilkan dalam jumlah besar dari proses sterilisasi dan klarifikasi Susilawati, \& Supijatmo. (2015). Untuk 1 (satu) ton minyak kelapa sawit dapat menghasilkan 2,5 ton limbah cair. Limbah ini berasal dari input air pada proses separasi, klarifikasi dan sterilisasi. Limbah ini umumnya memiliki suhu berkisar $70-80^{\circ} \mathrm{C}$, memiliki warna coklat pekat, mengandung butiran padat yang larut dan berupa koloid dari proses suspensi serta sisa minyak Saleh, A., \& Anggraini, M. (2016).

\section{Kepekaan Aspal Terhadap Temperatur}

Terdapat tiga pendekatan untuk mengungkapkan kondisi kepekaan temperatur aspal antara lain yaitu metode Penetration Index (PI) oleh Pfeiffer dan van Doormaal. PI ditentukan berdasarkan penetrasi dan titik lembek aspal Brown, S. (1990). Nilai PI ini dapat dihitung dengan rumus dibawah ini:

$P I=\frac{1952-500 \log p e n-20 S P}{50 \log p e n-S P-120}$

dengan :

PI = penetration index

pen $\quad=$ nilai penetrasi aspal 
SP $\quad=$ titik lembek aspal

Semakin rendah nilai PI, semakin peka suatu aspal terhadap temperatur. Aspal Keras (AC) pada umumnya memiliki nilai PI antara +1 sampai -1 . Aspal jenis airblown yang telah dikurangi sifat kepekaan temperaturnya dapat memiliki PI cukup tinggi Asphalt Institute (2001). Aspal semen yang memiliki PI kurang dari -2 sangat peka terhadap temperatur dan biasanya menampakkan sifat getas (brittle) pada suhu rendah, serta mudah retak pada musim dingin Toad, W., Waani., E, Joice (2016).

\section{METODE}

Penelitian ini dilakukan di laboratorium perkerasan jalan dengan menambahkan limbah pome pada aspal dengan melihat nilai propertis penetrasi aspal dan titik lembek. Adapun persentasenya sebesar 1\%,2\%,3\%,4\% dan 5\% dari berat aspal yang akan diuji Binamarga (2010). Aspal yang diuji merupakan aspal Pen.60/70 berasal dari pertamina dan limbah POME berasal dari PT.Asian Agri Pelalawan. Dalam menentukan suhu pencampuran dan pemadatan pada proses pencampuran, sifat propertis aspal selalu diperiksa minimal pemeriksaan penetrasi dan titik lembek agar dapat meningkatkan mutu perkerasan lentur Sihombing, Rouly A.V, (2014). Penelitian ini dilakukan dengan cara eksperimental kausal di Laboratorium dengan prosedur sebagai berikut:

1. Pemeriksaan Nilai Penetrasi.

Prosedur pengujian mengikuti PA-0301-76.

2. Pemeriksaan Titik Lembek.

Prosedur pemeriksaan mengikuti PA-0302-76.

\section{HASIL DAN PEMBAHASAN}

Dari hasil pengujian dilaboratorium didapatkan nilai penetrasi aspal sebagai berikut:

Tabel 1. Hasil Nilai Penetrasi Aspal

\begin{tabular}{c|c|c}
\hline No & Penambahan Limbah pome & Nilai Penetrasi (mm) \\
\hline 1 & $0 \%$ & 62,2 \\
\hline 2 & $1 \%$ & 58,4 \\
\hline 3 & $2 \%$ & 54,6 \\
\hline 4 & $3 \%$ & 51,5 \\
\hline 5 & $4 \%$ & 48,7 \\
\hline
\end{tabular}




\begin{tabular}{c|c|c}
\hline 6 & $5 \%$ & 45,6 \\
\hline
\end{tabular}

Sehingga hasil pada tabel 1 tersebut dapat digambarkan pada grafik berikut ini:

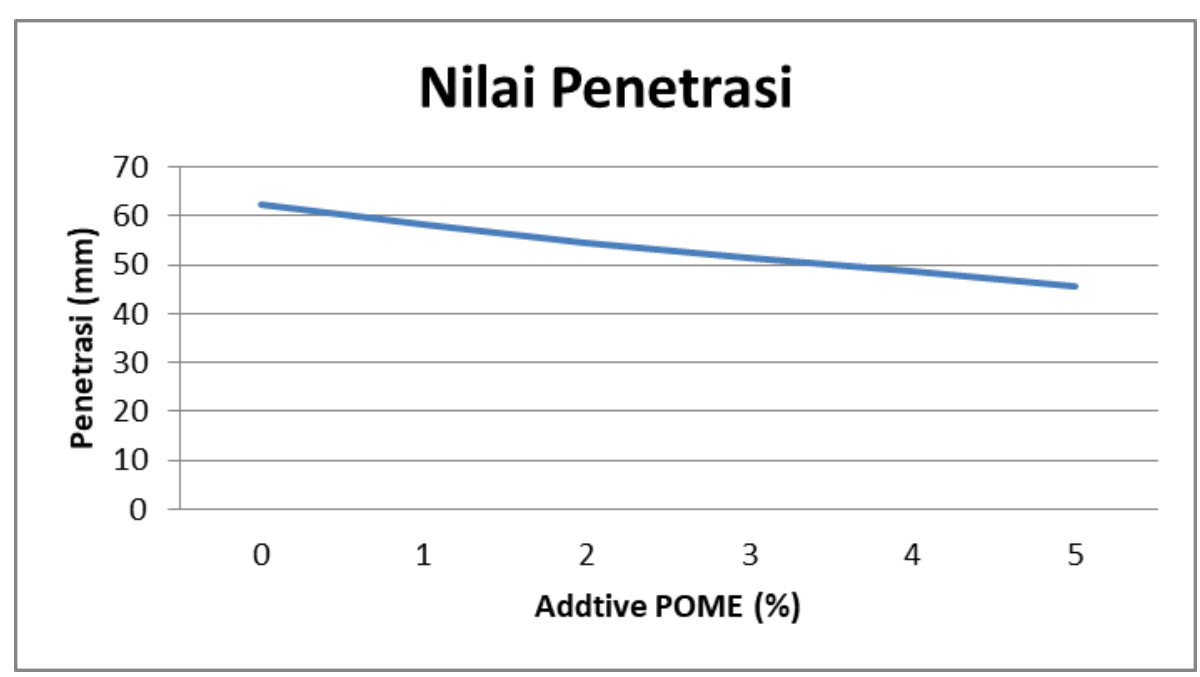

Gambar 1. Grafik Nilai Penetrasi dengan Penambahan Limbah Pome

Selain nilai penetrasi dilakukan juga pengujian titik lembek aspal yang hasilnya pada tabel 2 dibawah ini:

Tabel 2. Hasil Nilai Titik Lembek Aspal

\begin{tabular}{c|c|c}
\hline No & Penambahan Limbah pome & Titik Lembek $\left({ }^{\circ} \mathrm{C}\right)$ \\
\hline 1 & $0 \%$ & 50 \\
\hline 2 & $1 \%$ & 51 \\
\hline 3 & $2 \%$ & 52 \\
\hline 4 & $3 \%$ & 53 \\
\hline 5 & $4 \%$ & 54 \\
\hline 6 & $5 \%$ & 55 \\
\hline
\end{tabular}

Sehingga hasil pada tabel 2 tersebut dapat digambarkan pada gambar berikut ini:

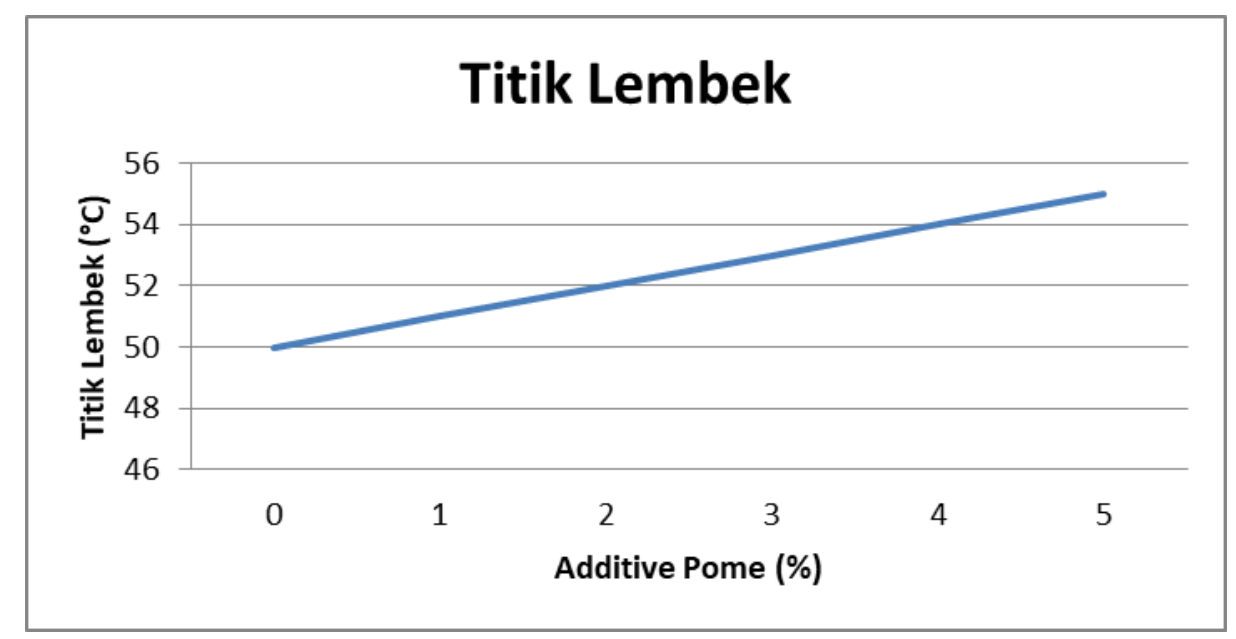


Gambar 2. Grafik Nilai Penetrasi dengan Penambahan Limbah Pome Dari hasil pemeriksaan penetrasi dan titik lembek tersebut maka dengan menggunakan rumus penetrasi indek maka didapat nilai Penetrasi Indeks (PI) aspal berikut:

Tabel 3. Hasil Nilai Penetrasi Indeks

\begin{tabular}{c|c|c}
\hline No & Penambahan Limbah pome & Nilai Penetrasi Indeks \\
\hline 1 & $0 \%$ & $-0,686$ \\
\hline 2 & $1 \%$ & $-0,590$ \\
\hline 3 & $2 \%$ & $-0,510$ \\
\hline 4 & $3 \%$ & $-0,413$ \\
\hline 5 & $4 \%$ & $-0,315$ \\
\hline 6 & $5 \%$ & $-0,245$ \\
\hline
\end{tabular}

Dari hasil nilai penterasi indeks yang didapat maka dilihat bahwa semakin besar penambahan limbah Pome maka nilai Penetrasi indeks akan semakin besar sehingga dari hasil penelitian ini dengan penambahan limbah pome maka aspal memiliki sifat sensitif terhadap suhu.

\section{SIMPULAN}

Penambahan limbah Pome dapat menurunkan nilai penetrasi aspal terlihat pada penambahan 5\% didapat nilai penetrasi aspal sebesar 45,6 mm dan Pada titik lembek aspal dengan penambahan limbah Pome maka nilai titik lembek mengalami kenaikan sehingg yaitu pada penambah $5 \%$ nilai titik lembek aspal sebesar $35^{\circ} \mathrm{C}$. Untuk nilai penetrasi indeks menunjukkan bahwa dengan penambahan limbah Pome nilai penetrasi mengalami peningkatan sehingga membuat aspal tersebut bersifat sensitif terhadap perubahan suhu.

\section{UCAPAN TERIMA KASIH}

Ucapan terima kasih kepada UP2M Fakultas Teknik yang merupakan perpanjangan tangan dari Lembaga Penelitian dan Pengabdian Masyarakat (LPPM) Universitas Lancang Kuning dan pihak laboratorium perkerasan jalan yang telah memberi dukungan terhadap penelitian ini.

\section{DAFTAR PUSTAKA}

Fauziah, M., \& Emsya, Y. D. (2010). Pengaruh Penggunaan WCO sebagai Bahan Peremaja RAP Terhadap Karakteristik Campuran RAP -Aspal Baru Bergradasi Superpave. Universitas Islam Indonesia.

Susilawati, \& Supijatmo. (2015). Pengelolaan Limbah Kelapa Sawit (Elaeis Guineensis Jacq) di Perkebunan Kelapa Sawit, Riau. Bul. Argrohorti, 3(2), 203-212. 
Rusbintardjo, G. (2013). Bahan Perkerasan Jalan (1st ed.). Semarang: UNISSULA Press.

Susilawati, \& Supijatmo. (2015). Pengelolaan Limbah Kelapa Sawit (Elaeis Guineensis Jacq) di Perkebunan Kelapa Sawit, Riau. Bul. Argrohorti, 3(2), 203-212.

Saleh, A., \& Anggraini, M. (2016). Pengaruh Penambahan Abu Tandan Kosong Kelapa Sawit (TKKS) Terhadap Nilai Penetrasi Indeks Aspal Pertamina Pen. 60/70. Siklus Teknik Sipil, 2(2), 104-113.

Brown, S. (1990). “The Shell Bitumen Handbook”. University of Nottingham.U.K.

Asphalt Institute 2001, Construction of Hot Mix Asphalt Pavement, MS-22, Six Edition, Lexington,Kentucky,USA.

Toad, W., Waani., E, Joice,2016, Kajian Pengaruh Suhu Permukaan Jalan Terhadap Kekuatan Geser tack Coat Pada Perkerasan Lentur, Jurnal Ilmiah Media Engineering, Vol.6No.1

Direktorat Jenderal Bina Marga, Spesifikasi Umum Binamarga 2010 Revisi 3, Kementrian Pekerjaan Umum Direktorat Jenderal Bina Marga.Jakarta

Sihombing, Rouly A.V, 2014,Pengaruh Temperatur Terhadap Daya Rekat Tack Coat, Jurnal; Jalan-Jembatan, Volume 31 No.1. 